\title{
Design and Implementation of MIPS Processor for LU Decomposition based on FPGA
}

\author{
Rusul S. Khalil and Safaa S. Omran
}

\begin{abstract}
The solution for a set of liner equations require to find the matrix inverse of a square matrix with same number of the linear equations, this operation require many mathematical calculations. To solve this problem, LU decomposition for the matrix is used, which computes two matrices, a lower triangle matrix and an upper triangle matrix. In this, paper a design for 32-bits MIPS (microprocessor without interlocked pipelined stages) processor with the required instructions that used to calculate the $\mathrm{LU}$ matrices. The design implemented using VHDL (Very high speed integrated circuit hardware description language) then integrated with FPGA (Field Programmable Gate Arrays) Xilinx Spartan 6. The results for the different parts of the processor are resented in the form of test bench waveform and the architecture of the system is demonstrated and the results was matched with theoretical results.
\end{abstract}

Index terms - Field Programmable Gate Array (FPGA), LU decomposition, VHDL, MIPS Processor.

\section{INTRODUCTION}

Matrix inversion is a well-known operation that be used by several algorithms, for example in solving simultaneous equations. The matrix inversion requires a lot of mathematical operations that cannot able to perform the operation in real time demand. An alternative method is by using the LU decomposition instead of the matrix inversion.

The LU-decomposition method is first "decomposes" matrix A into two matrices L and U. More accurately, if A is an $\mathrm{n} \times \mathrm{n}$ matrix, the first matrix is Lower triangular and the second matrix is an Upper triangular, both were an $\mathrm{n} \times \mathrm{n}$ matrices as shown below in the following set equations for a $3 \times 3$ matrix:

$$
\mathrm{A}=\mathrm{LU}
$$

$$
\begin{aligned}
& {\left[\begin{array}{lll}
a 11 & a 12 & a 13 \\
a 21 & a 22 & a 23 \\
a 31 & a 32 & a 33
\end{array}\right]=} \\
& {\left[\begin{array}{ccc}
1 & 0 & 0 \\
L 21 & 1 & 0 \\
L 31 & L 32 & 1
\end{array}\right]\left[\begin{array}{ccc}
U 11 & U 12 & U 13 \\
0 & U 22 & U 23 \\
0 & 0 & U 33
\end{array}\right]}
\end{aligned}
$$

Where, U11 = a11, U12 = a12, U13=a13

$\mathrm{Li} 1=\frac{a i 1}{U 11}, \mathrm{~L} 21=\frac{a 21}{U 11}, \mathrm{~L} 31=\frac{a 31}{U 11}$,

$\mathrm{U} 22=\mathrm{a} 22-\mathrm{L} 21 \times \mathrm{U} 12, \mathrm{U} 23=\mathrm{a} 23-\mathrm{L} 21 \times \mathrm{U} 13$ and

$$
\begin{aligned}
& \mathrm{a} 32=\mathrm{U} 12 \times \mathrm{L} 31+\mathrm{U} 22 \times \mathrm{L} 32 \\
& \mathrm{a} 33=\mathrm{L} 31 \times \mathrm{U} 13+\mathrm{L} 32 \times \mathrm{U} 23+\mathrm{U} 33
\end{aligned}
$$

For system of the equations $\mathrm{AX}=\mathrm{B}$, the motivation for $\mathrm{LU}$ decomposition is based on the observation of equations involving triangular matrices are easier to deal with .

When obtaining the LU decomposition of matrix A, then solving the system of $n$ linear equations in $n$ variables very effectively in the following two substitutions:

$$
\begin{aligned}
& \mathrm{AX}=\mathrm{B} \leftrightarrow \mathrm{LUX}=\mathrm{B}, \\
& \mathrm{UX}=\mathrm{Y} \text { (by many back substitutions) } \\
& \mathrm{LY}=\mathrm{B} \text { (by many forward substitutions) }
\end{aligned}
$$

The goal of this project is to build a 32-bit MIPS processor that be able to perform the LU decomposition. The processor is designed and implemented using VHDL.

Following sections are organized as follows: section two gives an explanation for the MIPS processor and the design procedure. Section 3 shows how the data were represented in this work; following sections give the results in details and the conclusions respectively.

\section{MIPS PROCESSOR}

Single cycle MIPS processor is a RISC (Reduced Instruction Set Computer) which can perform an entire instruction in one cycle. slowest instruction can limit cycle time. The MIPS processor contains 32-bits general purpose registers. In this paper a single cycle MIPS processor is designed and implemented to perform the mathematical requirements to apply the LU decomposition.

\section{A. MIPS Instruction Set Architecture (ISA)}

Microprocessors have two types of instruction set, first Reduced Instruction Set Computer (RISC) and second Complex Instruction Set Computer (CISC). RISC based processors have reduced number of instructions, large set of general purpose registers, instructions of fixed length and simplified address modes.

RISC processors works on the principle of load-store architecture. Whereas CISC based processors have more number of instructions with different varieties of address modes and variable length instructions. 
RISC processors when compared to CISC processors will consume less area to implement execute faster and have better performance making RISC processors suitable for system on chip circuitry [3] [4].

MIPS architecture contains 32-bits general-purpose registers where the operands are either registers or memory locations as shown in table 1, and instructions of length 32 bits. The processor, for word access it uses byte addressing.

TABLE I: MIPS general purpose registers

\begin{tabular}{|c|c|c|c|}
\hline Name & $\begin{array}{l}\text { Register } \\
\text { Number }\end{array}$ & Usage & $\begin{array}{l}\text { Preserved } \\
\text { on call }\end{array}$ \\
\hline \$zero & 0 & Constant value 0 & n.a \\
\hline \$at & 1 & $\begin{array}{l}\text { Reserved for the } \\
\text { assembler }\end{array}$ & n.a \\
\hline \$v0-\$v1 & 02-Mar & $\begin{array}{l}\text { Value for results and } \\
\text { expressions }\end{array}$ & no \\
\hline$\$ a 0-\$ a 3$ & 04-Jul & $\begin{array}{l}\text { Arguments } \\
\text { (procedures/factions) }\end{array}$ & yes \\
\hline$\$ \mathrm{t} 0-\$ \mathrm{t} 7$ & Aug-15 & Temporaries & no \\
\hline$\$ s 0-\$ s 7$ & $16-23$ & Saved & yes \\
\hline$\$ \mathrm{t} 8-\$ \mathrm{t} 9$ & $24-25$ & More temporaries & no \\
\hline$\$ \mathrm{k} 0-\$ \mathrm{k} 1$ & $26-27$ & $\begin{array}{l}\text { Reserved for the } \\
\text { operating system }\end{array}$ & n.a \\
\hline$\$ g p$ & 28 & Global pointer & yes \\
\hline$\$ s p$ & 29 & Stack pointer & yes \\
\hline$\$ f p$ & 30 & frame pointer & yes \\
\hline \$ra & 31 & Return pointer & yes \\
\hline
\end{tabular}

\section{B. Instruction Formats}

MIPS have 3 instruction format, namely: R-format, Iformat and J-format. Table 2 shows these instruction formats.

All instructions that do not have a memory address as an operand, target offset and an immediate value comes under Rformat instructions. Operations are performed on the data in the registers.

A total of 3 registers are required for the completion of an operation, two registers Rs and Rt as operands and the third register Rd to store the result of the operation. All arithmetic and shift instructions come under this format. Op-code ' 000000 ' is used by all the instructions, which are under this format [5].

Branch instructions, load and store instructions and all the instructions that have an immediate operand comes under Iformat instructions. Op-codes such as '000000', '0100xx' and '00001x' are not used by I-format instructions [6].

Jump instructions $\mathrm{J}$ and $\mathrm{JAL}$ come under $\mathrm{J}$-format instructions. The operands of these instructions are specified by memory address. Op-code '00001x' is used to specify Jformat instructions [5].

TABLE 2: MIPS Instruction format

\begin{tabular}{lllllll}
\hline \hline $\begin{array}{l}\text { Field } \\
\text { size }\end{array}$ & 6-bits & 5-bits & 5-bits & 5-bits & 5-bits & 6-bits \\
\hline R-Type & op & Rs & Rt & Rd & shamt & funct \\
I-Type & op & Rs & Rt & 16-bits Imm & \\
J-Type & op & 26-bits Addr & & & \\
\hline \hline
\end{tabular}

Where,

- op: Operation code (also known as opcode) that selects a certain operation.

- rs: First source register.

- $\quad \mathrm{rt}$ : Second source register.

- rd: Destination register.

- func: Is used together with the opcode to select an arithmetic instruction.

- $\quad$ address: the 26-bits address which is used in jump instruction.

- Shamt: used for shift instruction to hold the shift amount

- Imm: 16 bits address is used within data transfer and control instructions.

\section{Single cycle MIPS Processor Design}

A single-cycle MIPS is a type of MIPS microarchitecture.

MIPS executes every instruction in one clock cycle [7], where:

1) Slowest instruction can limit cycle timing which make shorter instructions execute in one of the unnecessary long cycle [8].

2) Additionally, data-path resource can't be used more than once per each instruction, else must be duplicated [9]. And because of it the signle cycle design will need:

- Instruction and data as two memories.

- And two adders, one that computes value of $(\mathrm{PC}+4)$ while the other computes branch target address.

The MIPS implementation consists of two different types of logic elements:

1) Combinational: an elements that operate on data values such as ALU and adder.

2) Sequential: an elements that have and hold a state like register file, instruction memory and data memory [8] [10].

For design simplicity, an edge-triggered clocking methodology is assumed that allow state element to read and write at the same clock cycle. Fig. 1 shows two state elements placed round combinational logic, that operate in single clock cycle.

signals must transit from state element one, through combinational logic to the state element two in one clock cycle. The time is necessary for signals to reach state element two that defines the length of the clock cycle [11].

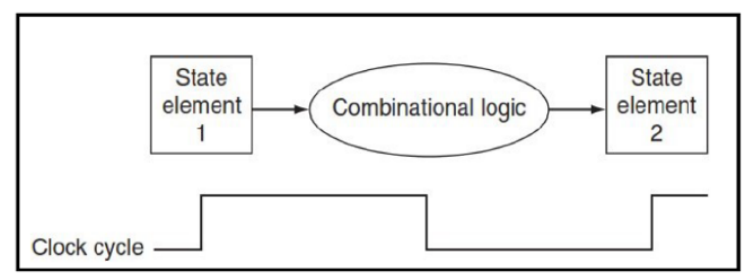

Figure. 1. State elements, ccombinational logic, and clock cycle are closely related [11]. 
The MIPS microarchitecture is divided into two interacting parts:

1) Datapath: 32-bits datapath implicate elements such as registers, memories, sign-extenders, multiplexers. datapath elements as showing below:

a) Program counter (PC): it is a 32bit register and its output represents the address of the current instruction (instr) while input automatically incremented by 4 (depends on instr size 4 bytes) to read PC next represent linstruction address.

b) Instruction memory take 32 bit address from a) port.

Program counter register and read 32bit data in output

c) Register file combine of 32 registers each. Having two reading ports (RD1) and (RD2) and one writing port (WD3). Reading ports (RD1) and (RD2) take 5bit address inputs (A1) and (A2) which select one of the registers to be read on the reading output ports. Writing port will take 5bit address input (A3) which select one register to which the 32 bit on (WD3) input port will be written if the (WE) signal is one on the raising of the clock signal.

d) Data memory have one output reading port (RD) and one input writing port (WR). 32-bit data at input (WR) port is written to the memory location which can be specified by address (A) if (WE) signal is one at the raising of the clock signal.

e) Adder such an Arithmetic Unit (AU) with the label $(+)$ to indicate that it is always performs an add operation on its inputs.

f) Multiplexer (Mux) used to chose only one input from multi inputs and pass that to output. Mux select one line that controlled by a signal which provided by control unit.

g) Sign extender simply copy the sign bit (most significant bit) of half word or byte to all upper word output.

h) AU (Arithmetic Unit) designed to execute all of the arithmetic instructions. arithmetic unit (AU) consists of addition and subtraction (add/sub) which all versions of FPGA kits supported for these operations, multiplication (mul) which some types of FPGA kits support like (Virtex 4, Virtex 7, spartan 3E and spartan 6 ), also Spartan 6 device and any top series family can support division (div).

2) Control unit (CU): receives the "opcode" "instr 31:26" and function "instr5:0" fields of current instruction which is received from instruction memory. The design consists of eight signals ( 8 control signals), (alu control) signal used to for arithmetic operation as shown in table 4 .

Designing set of instructions as shown in table 3 and figure for internal architecture, which is suitable to perform LU decomposition.

TABLE 3: Instruction set

\begin{tabular}{llllllll}
\hline \hline Instruct & SW & LW & AD & ADDi & SUB & MUL & DIV \\
ions & RD, R & RD, R & D & RD, R & RD, & RT, & RT, \\
& S,IM & S,IM & RD, & S,IM & RS, R & RS, & RS, \\
& M & M & RS, & M & T & RD & RD \\
& & & RT & & & & \\
\hline
\end{tabular}

\begin{tabular}{|c|c|c|c|c|c|c|c|}
\hline Opcod & 1010 & 1000 & 0 & 1000 & 0 & 0 & 0 \\
\hline $\mathrm{e}$ & 11 & 11 & & & & & \\
\hline $\begin{array}{l}\text { Regwri } \\
\text { te }\end{array}$ & 0 & 1 & 1 & 1 & 1 & 1 & 1 \\
\hline Regdst & 0 & 0 & 1 & 0 & 1 & 1 & 1 \\
\hline $\begin{array}{l}\text { ALUS } \\
\text { RC }\end{array}$ & 1 & 1 & 0 & 1 & 0 & 0 & 0 \\
\hline ZERO & 0 & 0 & 0 & 0 & 0 & 0 & 0 \\
\hline $\begin{array}{l}\text { MEM } \\
\text { Write }\end{array}$ & 1 & 0 & 0 & 0 & 0 & 0 & 0 \\
\hline $\begin{array}{l}\text { MEMt } \\
\text { oRegist } \\
\text { er }\end{array}$ & 0 & 1 & 0 & 0 & 0 & 0 & 0 \\
\hline $\begin{array}{l}\text { ALUop } \\
\text { code }\end{array}$ & 0 & 0 & 10 & 0 & 10 & 10 & 10 \\
\hline $\begin{array}{l}\text { Functio } \\
\mathrm{n}\end{array}$ & $\mathrm{x}$ & $\mathrm{x}$ & $\begin{array}{l}1000 \\
00\end{array}$ & $\mathrm{x}$ & $\begin{array}{l}1000 \\
10\end{array}$ & $\begin{array}{l}10010 \\
0\end{array}$ & $\begin{array}{l}1001 \\
01\end{array}$ \\
\hline type & $\begin{array}{l}\text { I- } \\
\text { Type }\end{array}$ & $\begin{array}{l}\text { I- } \\
\text { Type }\end{array}$ & $\begin{array}{l}\text { R- } \\
\text { Type }\end{array}$ & $\begin{array}{l}\text { I- } \\
\text { Type }\end{array}$ & $\begin{array}{l}\text { R- } \\
\text { Type }\end{array}$ & $\begin{array}{l}\text { R- } \\
\text { Type }\end{array}$ & $\begin{array}{l}\text { R- } \\
\text { Type }\end{array}$ \\
\hline $\begin{array}{l}\text { Descri } \\
\text { ption }\end{array}$ & $\begin{array}{l}\text { Save } \\
\text { word } \\
\text { in } \\
\text { mem } \\
\text { ory }\end{array}$ & $\begin{array}{l}\text { Load } \\
\text { word } \\
\text { from } \\
\text { mem } \\
\text { ory }\end{array}$ & $\begin{array}{l}\text { Addi } \\
\text { tion } \\
\text { oper } \\
\text { ation }\end{array}$ & $\begin{array}{l}\text { Addit } \\
\text { ion } \\
\text { imme } \\
\text { diate } \\
\text { opera } \\
\text { tion }\end{array}$ & $\begin{array}{l}\text { Subtr } \\
\text { actio } \\
\mathrm{n} \\
\text { oper } \\
\text { ation }\end{array}$ & $\begin{array}{l}\text { Multi } \\
\text { plicati } \\
\text { on } \\
\text { operat } \\
\text { ion }\end{array}$ & $\begin{array}{l}\text { Divi } \\
\text { sion } \\
\text { oper } \\
\text { ation }\end{array}$ \\
\hline
\end{tabular}

TABLE 4: Function of (alu control) signal

\begin{tabular}{ll}
\hline \hline Code & Operation \\
\hline 0 & mul \\
1 & div \\
10 & add \\
11 & not used \\
100 & not used \\
101 & not used \\
110 & sub \\
111 & not used \\
\hline \hline
\end{tabular}

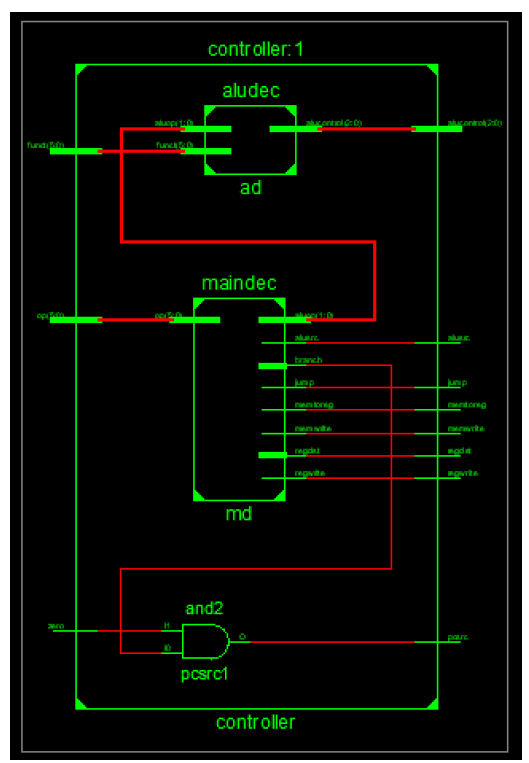

Figure. 2. Control unit internal architecture 


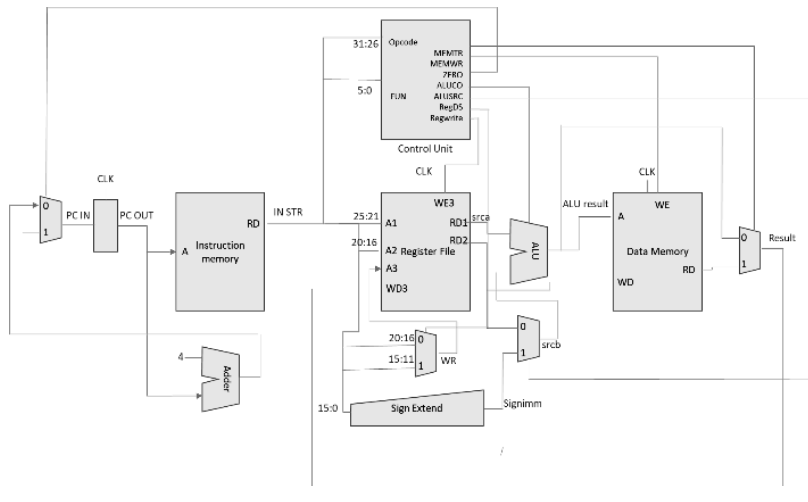

Figure. 3. MIPS processor for LU decomposition

\section{DATA REPRESENTATION}

There are two types of data representation (fixed point and floating point).

The arithmetic of fixed point is an extension of integer representation that allows relatively reducing the range of numbers with a constant precision as well as implementation at low complexity.

The use of arithmetic of the floating point is much expensive in regarding hardware and it leads to inefficient designs especially to implement FPGA.

The word length of the fixed point that has been used is equal to 32 bits divided into 20 bits fraction point, 11 bits integer part and last bit been sign number. Figure 4 shows the design of fixed point format.

Fixed point arithmetic results in efficient hardware designs. Our design uses two's complement fixed point arithmetic, The data lines used in implementation for fixed point arithmetic consist of an integer part, a fractional part and a sign bit.

\begin{tabular}{|l|cc|cc|}
\multicolumn{1}{c|}{ Sign } & \multicolumn{2}{|c|}{ Integer value } & \multicolumn{2}{c|}{ decimal fraction } \\
\hline 1 bit & \multicolumn{2}{|c|}{ 20 bits } \\
\hline 31 & 30 & $\begin{array}{c}20 \\
\text { Figure. 4. Fixed point format }\end{array}$
\end{tabular}

\section{SimUlation RESUlts}

The designed processor was implemented using the Xilinx ISE design suite14.7 tool. Figure 5 shows the RTL schematic top level and figure 6 shows the RTL schematic for architecture of the MIPS processor.

To test the designed processer, a matrix has been implemented using VHDL and Xilinx Spartan 6 by using a

set of instructions that calculated the LU decomposition, The A matrix and its LU decomposition is shown in equation (11) for $3 \times 3$ matrix which also processor can perform up to $8 \times 8$ matrix. the results was matched with theoretical results as there is no research/paper been done before for LU decomposition to do a comparison.

$$
A=\left[\begin{array}{ccc}
1 & 2 & 4 \\
3 & 8 & 14 \\
2 & 6 & 13
\end{array}\right]=L\left[\begin{array}{lll}
1 & 0 & 0 \\
3 & 1 & 0 \\
2 & 1 & 1
\end{array}\right] U\left[\begin{array}{lll}
1 & 2 & 4 \\
0 & 2 & 2 \\
0 & 0 & 3
\end{array}\right]
$$

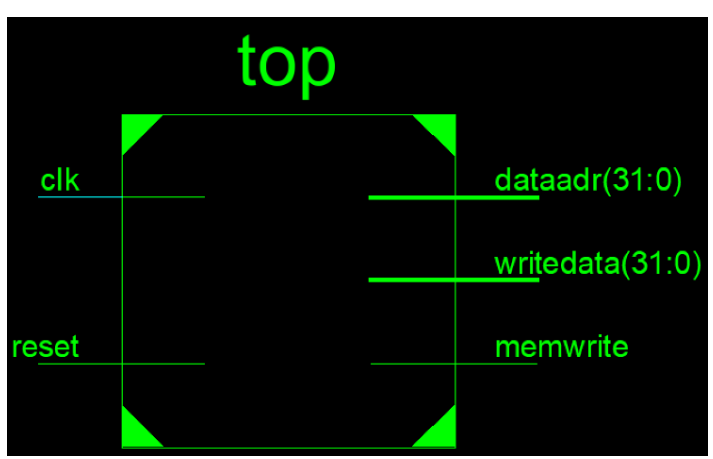

Figure. 5. RTL top level

Figure 7 shows the test bench for the simulation waveform for the matrix A and its LU decomposition and in figure 8 shows the resource required for implemented design.

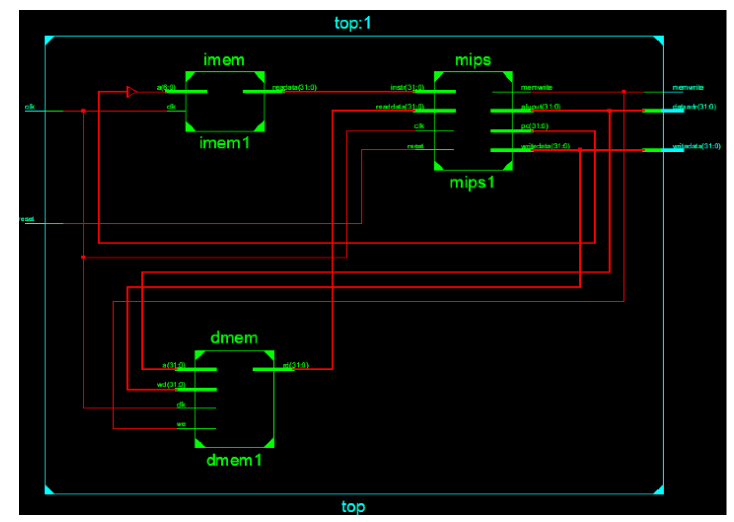

Figure. 6. RTL schematic for the MIPS processor

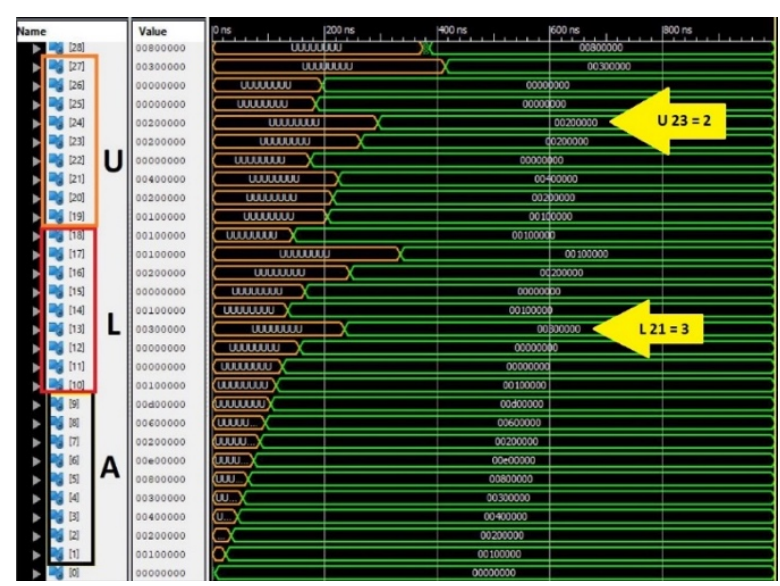

Figure. 7. Test Bench results 


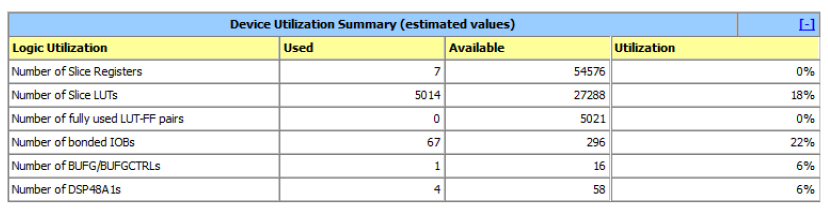

Figure. 8. Summarizes the FPGA resources

\section{CONCLUSIONS}

In this paper, 32-bit MIPS processor was designed with certain instructions that are sufficient to perform the LU decomposition operation by using VHDL Xilinx ISE software language and FPGA kit Spartan 6. The implemented design tested and gives correct results at running frequency $50 \mathrm{MHz}$

\section{REFERENCES}

[1] A. Yang, C. Liu, J. Chang, X. Guo, "Parallel LU Decomposition Method and It's Application in Circle Transportation", Journal of softwate, vol.5, no.11, 2010.

[2] M. T. Goodrich, “Algorithm Analysis and Design”, Beijing: People's Posts \& Telecom Press, 2006.

[3] K. Bhattacharyya, R. Biswas, A. S. Dhar, S. Banerjee "Architectural design and FPGA implementation of radix-4 CORDIC processor," Microprocessors and Microsystems, Vol. 34, pp. 2-4, 2010.

[4] J. L. Hennessy, J. Norman, Steven Przybylski, Christopher Rowen, Thomas Gross, Forest Baskett, and John Gill. "Mips: A microprocessor architecture", In ACM SIGMICRO Newsletter, vol. 13, pp. 17-22, 1982.

[5] M. N. Topiwala, N. Saraswathi "Implementation of a 32-bit MIPS based RISCprocessor using cadence", IEEE International Conference on Advanced Communication Control and Computing Technologies (ICACCCT), 2014.

[6] M. Mounika, A. Shankar "Design \& implementation of 32-bit Risc (MIPS) processor", International Journal of Engineering Trends and Technology (IJETT) - Vol. 4 Issue 10, SSN: 2231, Oct 2013.

[7] H. S. Mehta, "Design of MIPS Processor," MSc. Thesis, California State University, Northridge, California, USA, 2012.

[8] J. L. Hennessy, D. A. Patterson, "Computer Organization and Design: The Hardware/Software Interface", USA: Morgan Kaufmann: 4th ed., Waltham, 2012.

[9] R. Srinidhi, "MIPS Processor Implementation," MSc. Thesis, California State University Northridge, California, USA, 2012.

[10] V. Robio, "A FPGA Implementation of A MIPS RISC Processor for Computer Architecture Education," MSc. thesis, New Mexico State University, Las Cruses, New Mexico, America, 2004.

[11] C. K. Singh, S. H. Prasad, and P. T. Balsara, "A fixed-point implementation for QR decomposition," Proc. IEEE Dallas Workshop Design Applicat. Integration Software, p. 75-78, 2006.

[12] D. A. Patterson, J. L. Hennessy, "Computer organization and design: the hardware software interface" Morgan Kaufmann, 2013.

[13] B. C. Alecsa and A. D. Ioan, "FPGA Implementation of a Matrix Structure for Integer Division," in IEEE, Galati, Romania, 2010.

[14] J. Neenu, S. Sabarinath, K. Sankarapandiammal "FPGA based implementation of high performance architectural level low power 32-bit RISC core" in IEEE International Conference on Advances in Recent Technologies in Communication and Computing, 2009.

[15] V.N.Sireesha, D. Santosh" FPGA Implementation of A MIPS RISC Processor" in Int.J.Computer Technology \& Applications, Volume 3 (3), 1251-125, 2012

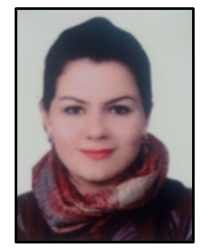

Rusul Saad Khalil was born in Baghdad, Iraq in 1992. She graduated from AlMamon University college in 2014, and now studying master at Electrical Engineering College / Middle Technical University, Baghdad, Iraq, her main interest in Computer Architecture Design, Computer engineering, embedded system and design.

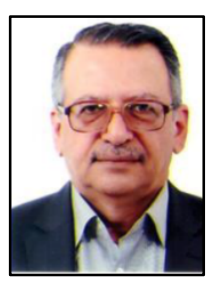

Safaa S Omran was born in Baghdad, Iraq in 1956. He graduated from University of Baghdad

in 1978, and then he got the MSc from the same University in 1984 . He is now a professor working at the Electrical Engineering College / Middle Technical University, Baghdad, Iraq. His main interest working researches are in the field of microprocessor design for embedded systems, Image processing and cryptography system design. 